\title{
DOBUTAMINE AND GENERAL ANAESTHESIA: A STUDY OF THE RESPONSE OF ARTERIAL PRESSURE, HEART RATE AND RENAL BLOOD FLOW*
}

\author{
Kenneth M. Leighton and Caroline Bruce $\oint$
}

SINCE THE FIRST REPORTS on dobutamine by Tuttle, ${ }^{1-3}$ a number of investigators have studied the effects of this new sympathomimetic amine. The assertion that the drug has greater inotropic than chronotropic effects has been investigated in man and experimental animals with conflicting results. ${ }^{4-8}$

Dobutamine is a derivative of isopropylnoradrenaline which is itself related to dopamine. Isopropylnoradrenaline and dopamine have been used in the treatment of acute cardiovascular failure associated with low cardiac output. One of the advantages claimed for dopamine is a selective reduction in renal vascular resistance with consequent improvement in perfusion..$^{9,10}$ It was hoped that dobutamine might effect a comparable improvement.

It is well documented that general anaesthesia may alter responses which follow physiological stimuli and the administration of some drugs. ${ }^{11,12}$ The only reported study of the effect of dobutamine upon renal perfusion was conducted during chloralose and pentobarbitone anaesthesia. ${ }^{13}$ It appeared pertinent, therefore, to observe the effect of the drug upon renal blood flow during conventional general anaesthesia with controlled arterial blood gas tensions.

\section{Method}

The experiments were conducted on dogs (average weight $20 \mathrm{~kg}$ ). Arterial blood pressure, heart rate and total renal blood flow were studied.

Renal blood flow was measured by means of a Doppler shift ultrasonic flow probe. $\$$ Following surgery the animals were permitted to recover for several days (not less than four) before experimental observations were made.

The general experimental methodology has been described elsewhere. In brief, body temperatures were maintained at $38.5^{\circ} \mathrm{C}$ and $\mathrm{Pa}_{0_{2}}$ greater than $100 \mathrm{~mm} \mathrm{Hg}$; $\mathrm{Pa}_{\mathrm{CO}_{2}} 30-40 \mathrm{~mm} \mathrm{Hg} ; \mathrm{pH}$ 7.35-7.46. The animals were artificially ventilated by means of a Bird Mark 8 ventilator.

Anaesthesia was induced with thiopentone $(20 \mathrm{mg} / \mathrm{kg})$ and maintained thereafter by halothane and oxygen, or halothane, nitrous oxide, oxygen or by the intravenous administration of alphaprodine. The latter drug was given as a bolus of $1.0-1.5 \mathrm{mg} / \mathrm{kg}$ and continued as an infusion in 5 per cent dextrose and distilled water. One $\mathrm{mg} / \mathrm{min}$ of alphaprodine was administered in this manner. Fine adjust-

- Supported by a grant-in-aid of research awarded by the British Columbia Heart Foundation. tDepartments of Anaesthesia and Pharmacology, Faculty of Medicine, The University of British Columbia, Vancouver, Canada. V6T IW5

$\$$ Parks Electronics, Beaverton, Oregon. 
ments to the rate of infusion were required to regulate the depth of anaesthesia, but the net rate of administration remained $1 \mathrm{mg} / \mathrm{min}$.

Mean arterial pressures were stabilized at $75-100 \mathrm{~mm} \mathrm{Hg}$ before the administration of dobutamine.

Dobutamine was administered intravenously in a continuous infusion with 5 per cent dextrose and distilled water. Doses ranged from 5 to $50 \mu \mathrm{g} / \mathrm{kg} / \mathrm{min}$ (see Tables). In animals anaesthetized with alphaprodine two separate intravenous routes were established.

Dobutamine was infused for varying periods of time, ranging from 5 to 20 minutes (see Tables).

Neuromuscular blockade was employed to prevent random movements following dobutamine administration. Such movements are frequently observed during anaesthesia after the administration of catecholamines. Pancuronium $(0.08 \mathrm{mg} /$ $\mathrm{kg}$ ) was given at least 10 minutes before dobutamine infusion. D-tubocurare $(0.5$ $\mathrm{mg} / \mathrm{kg}$ ) was substituted for pancuronium in two dogs and no difference was noted in the response to dobutamine. These two dogs are included in the results.

\section{Halothane}

\section{Results}

No difference was noted in the response to dobutamine between halothane and halothane, nitrous oxide anaesthesia. In both groups (See Figure 1) the initial response after the commencement of dobutamine infusion was a minor decrease in rate and this appeared within one minute of the start of the infusion. Thereafter, heart rate increased until a plateau was reached and at this point the rate remained relatively steady for such time as dobutamine continued to be infused. The mean increase following $20 \mu \mathrm{g} / \mathrm{kg}$ for 20 minutes in two animals anaesthetized with halothane was 131.6 per cent. Tachycardia consistently followed dobutamine administration and it was uninfluenced by concomitant nitrous oxide (see Figure 1). Other dysrhythmias were observed during both anaesthetic techniques (inhalation and narcotic). These dysrhythmias were ventricular, multifocal and, in general, disappeared with the onset of tachycardia.

Arterial blood pressure rose in all animals after the start of dobutamine infusion (see Figure 1 and Tables I, II and III). The first response of arterial pressure after dobutamine was a transient decrease from the resting value. Thereafter, pressure rose in all animals.

Renal blood flow in this group of animals was increased after dobutamine was started ( see Figure 1). In the case of the administration of $20 \mu \mathrm{g} / \mathrm{kg} / \mathrm{min}$, the mean increase for five experiments after 20 minutes was 39.12 per cent.

\section{Alphaprodine}

In those animals which were anaesthetized with alphaprodine alone, the administration of dobutamine was followed by a transient fall in arterial pressure. This quickly changed to an increase over the resting level (for amount of increase please see Table III).

Following dobutamine, in the alphaprodine group of animals, an increase in heart rate was observed but this was less than that seen in the halothane group. 

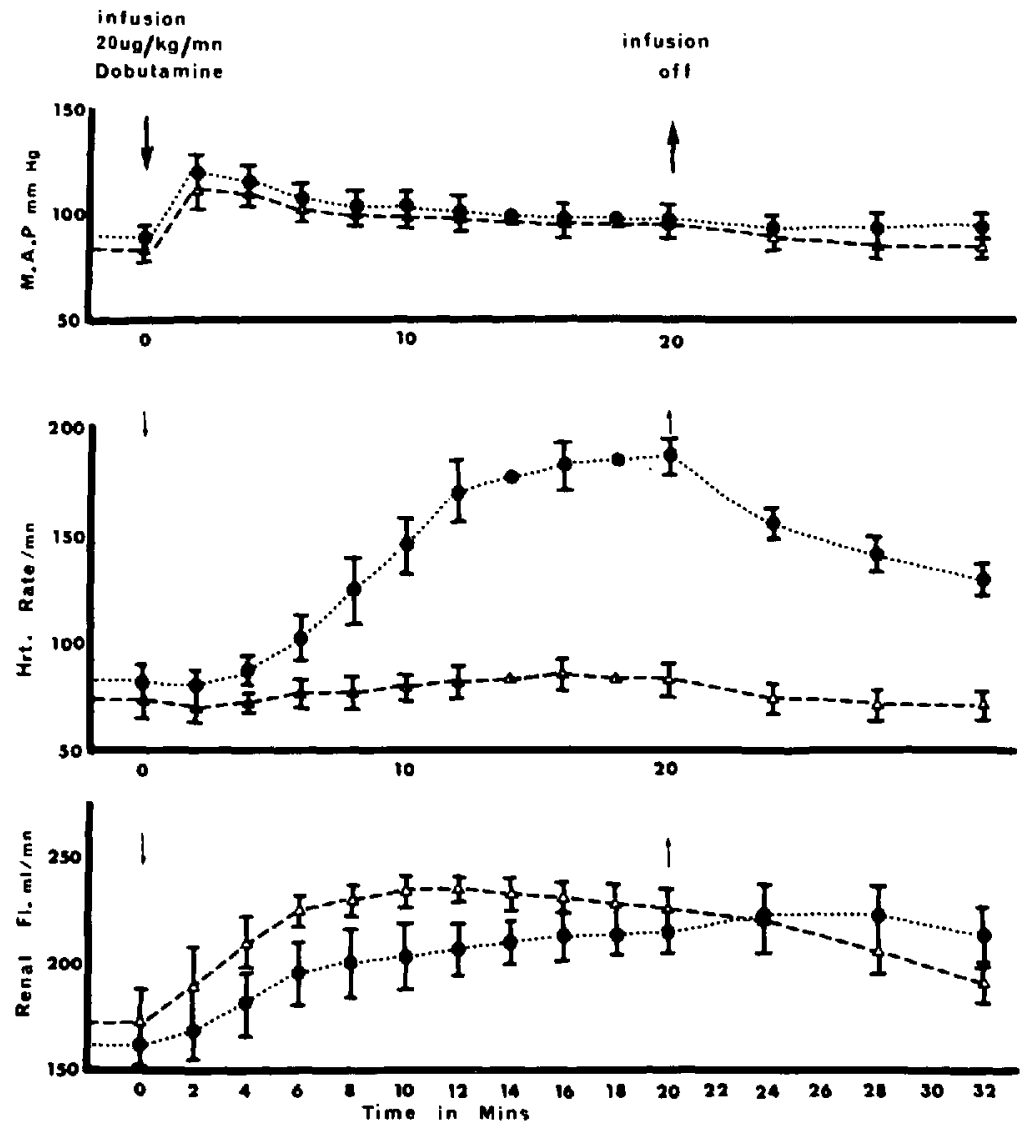

Figure 1. Response of mean arterial pressure, heart rate and renal blood flow to $20 \mu \mathrm{g} / \mathrm{kg} / \mathrm{min}$ of dobutamine administered for 20 minutes. Dotted line $=$ halothane, halothane and nitrous oxide (means and standard errors of five experiments). Dashed line $=$ alphaprodine (means and standard errors of four experiments). Note only minor increase in rate during alphaprodine anaesthesia.

The mean increase in 4 experiments after $20 \mu \mathrm{g} / \mathrm{kg} / \mathrm{min}$ for 20 minutes was 22.7 per cent.

Dysrhythmias were observed of the same type as those seen during halothane anaesthesia. They reverted in the same manner with the onset of tachycardia.

During dobutamine infusion, the mean increase in renal blood flow was 39.57 per cent in this group of animals.

\section{Discussion}

Cardiac glycosides benefit both acute and chronic heart failure: sometimes a more powerful myocardial stimulant is necessary. A drug which increased myocardial contractility without inducing a concomitant increase in rate and the potential for other disturbances of rhythm would prove particularly useful for this purpose. 


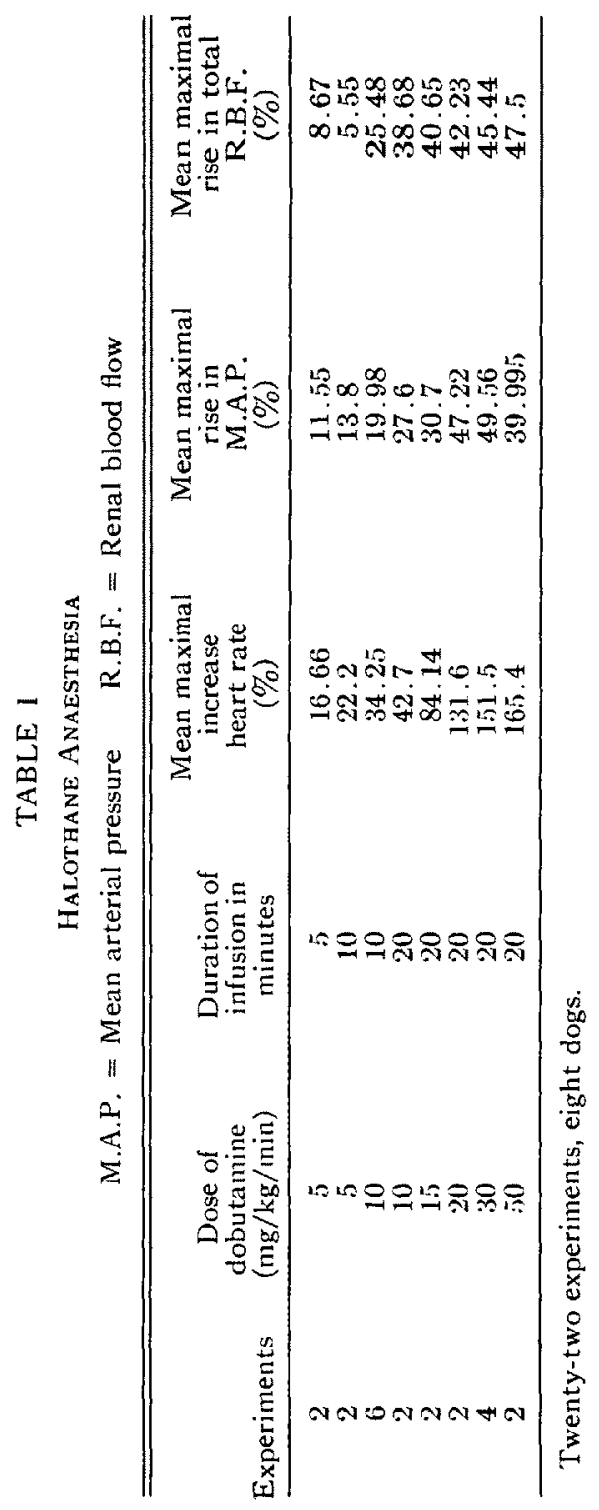



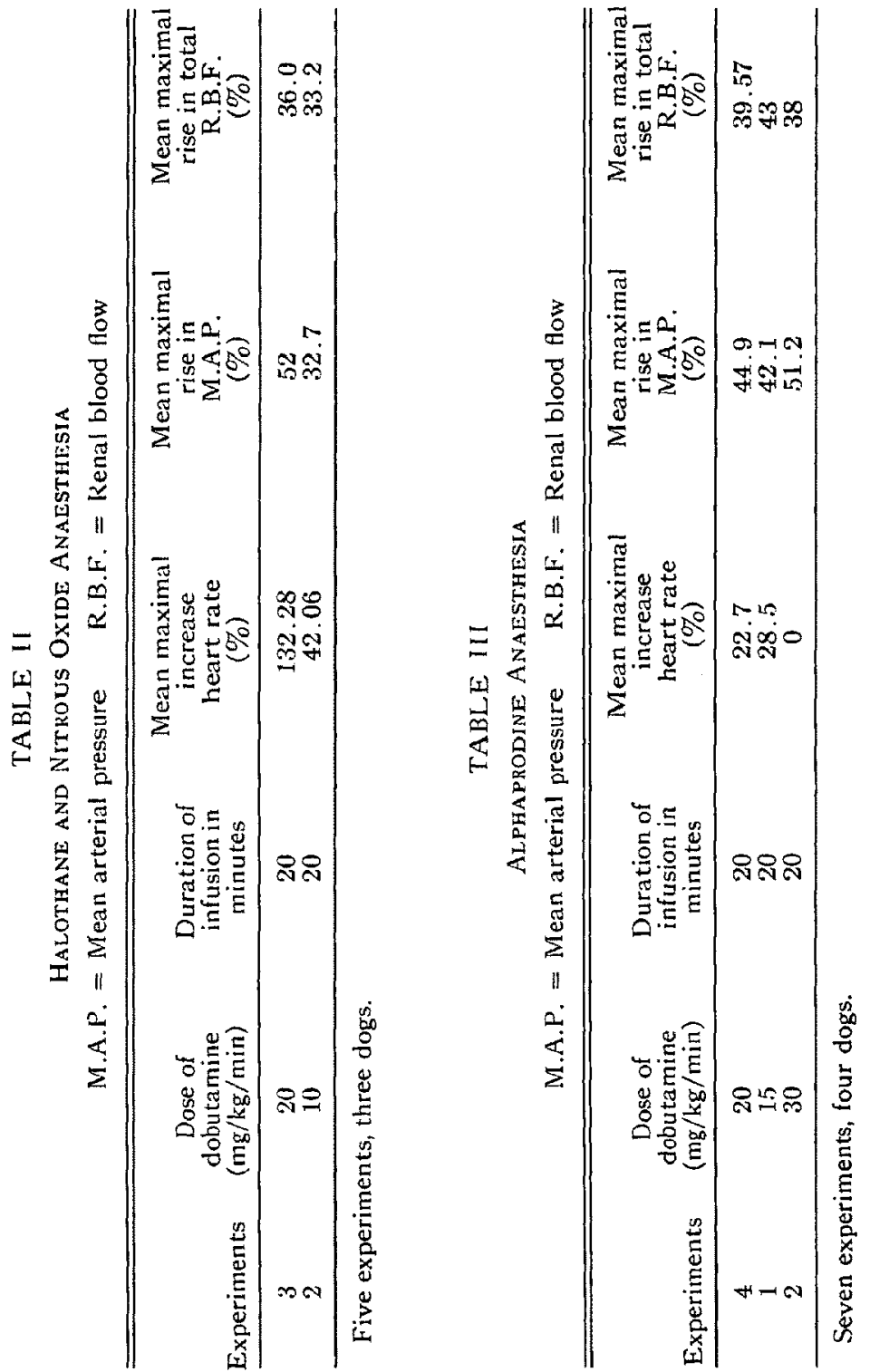
The need for such an agent is encountered in anaesthetic practice. Such situations arise most often in association with cardiac surgery, particularly when cardiopulmonary bypass is discontinued. ${ }^{\mathbf{5}}$

In this emergency, catecholamines have been employed for their $\beta_{1}$-activity. Adrenaline, noradrenaline, isopropylnoradrenaline and dopamine have all been used to improve myocardial performance. None of these has satisfied the requirements of an ideal agent in the separation of chronotropic and inotropic effects. While they improve myocardial contractility, these drugs all induce disturbances in rate and rhythm. Peripheral circulatory responses are often significant as well. ${ }^{14}$

Adrenaline and noradrenaline have powerful inotropic actions but these are accompanied by severe increases in rate and disturbances of rhythm. The peripheral circulatory effects of both agents are, of course, profound and often detrimental to the acutely failing cardiovascular system.

Isopropylnoradrenaline has enjoyed some popularity in the treatment of the acutely failing heart since it increases myocardial performance more than the most powerful glycoside. ${ }^{15}$ However, its use is accompanied by a marked increase in rate and other dysrhythmias. Since it causes peripheral vasodilatation, particularly in skeletal muscle, and thus may produce a marked reduction in arterial pressure, isopropylnoradrenaline is not the ideal drug for the treatment of this form of heart failure.

Dopamine, the third of the endogenous catecholamines, has been employed for this purpose. ${ }^{9}$ Dopamine stimulates both $\alpha$ - and $\beta$-adrenergic receptors as well as specific dopaminergic receptors. ${ }^{5}$

The administration of dopamine is followed by increased myocardial contractility and raised peripheral resistance. The latter is mediated by $\alpha$-adrenergic receptors. ${ }^{5}$ The renal vascular bed, however, responds with diminished resistance. Increased renal plasma flow has been shown to follow dopamine administration. ${ }^{9}$

Dopamine, therefore, would seem to be a satisfactory agent for the management of acute heart failure. Unfortunately the drug gives rise to dysrhythmias almost as frequently as isopropylnoradrenaline. ${ }^{16.17}$ The only distinct advantage which dopamine has over isopropylnoradrenaline lies in its renovascular effects.

It was as a result of the generally unsatisfactory response of the acutely failing circulation to the agents mentioned above that dobutamine was developed.<smiles>CNCC(O)c1ccc(O)cc1</smiles>

Adrenaline<smiles>CC(CCc1ccccc1)NCc1ccc(O)cc1</smiles>

DL-3,4-dihydroxyl-N-[-3-(-4-hydroxyphenyl)-1-methyl-n-propyl] phenylethylamine hydrochloride (Dobutamine) 


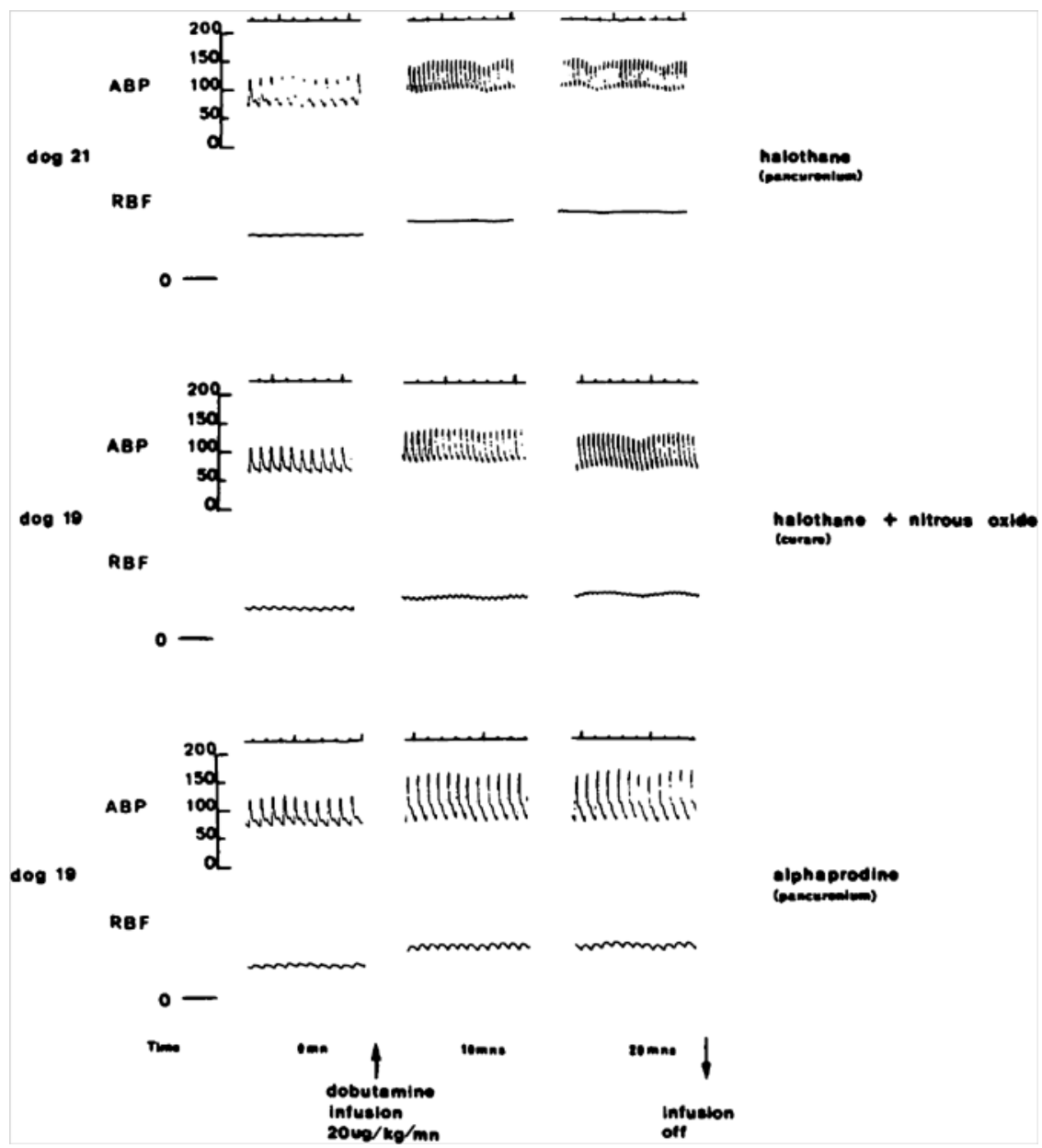

Figure 2. Representative tracings showing response of arterial pressure (ABP) and renal blood flow (RBF) to the infusion of dobutamine, $20 \mu \mathrm{g} / \mathrm{kg} / \mathrm{min}$ for 20 minutes. Note similar response with halothane and halothane, nitrous oxide. Minimal increase in rate during alphaprodine anaesthesia can be contrasted with more marked tachycardia observed during halothane anaesthesia.

Claims for a preponderance of $\beta_{1}$ over $\beta_{2}$ agonist activity have been made for the drug by a number of investigators. ${ }^{3.4}$ Other workers have observed that, while the administration of dobutamine is accompanied by an apparent increase in myocardial contractility, there is still a marked increase in rate which follows the administration of this agent. ${ }^{5}$

Dopamine appears to improve renal perfusion. This is a desirable attribute for any drug used in the treatment of heart and circulatory failure. It appeared worthwhile, therefore, to observe this index of circulatory improvement following the administration of dobutamine during anaesthesia.

It seems clear from the studies reported here that the response to the intravenous 
infusion of dobutamine during general anaesthesia is influenced to some extent by the anaesthetic agent employed.

Some rise in heart rate is observed with both anaesthetic techniques studied here. In the case of narcotic anaesthesia (using alphaprodine) the rise is comparatively minor. However, during the administration of halothane there is a much more significant increase in rate.

Mean arterial blood pressure rises with both alphaprodine and halothane anaesthesia after dobutamine. The increase is not appreciably greater in the presence of one or other anaesthetic.

Renal blood flow is increased following the administration of dobutamine. The increase appears to be the same with both techniques and is appreciable (mean increase 39 per cent). This result is at variance with observations : fported by Robie et al. who noted no more than an 8 per cent increase in renal blood flow following direct intra-arterial injection of dobutamine into the renal arteries of dogs during pentobarbitone anaesthesia. ${ }^{13}$

It is possible that this difference can be explained by the different anaesthetic techniques employed since barbiturates have been shown to produce a fall in spanchnic blood flow and renal perfusion. ${ }^{18}$ However, unless blood gas tensions are maintained within physiological limits, vascular responses cannot be satisfactorily compared. In the series of experiments which are the subject of this report, blood gases were repeatedly measured and kept within normal limits by adjusting ventilation.

Dobutamine does not appear to satisfy the demand for minimal chronotropic activity. During alphaprodine anaesthesia however, there is very much less rate increase than is found with halothane. This may represent the well-documented sensitizing effect of some anaesthetics to the cardiac actions of catecholamines. The occurrence of ventricular ectopic rhythms with both anaesthetics is disturbing evidence of the failure to isolate inotropic activity.

From these experiments we conclude that dobutamine does improve renal perfusion during general anaesthesia with halothane or alphaprodine in the presence of neuromuscular blockade produced by d-tubocurare or pancuronium. The addition of nitrous oxide to halothane does not alter the renal response to dobutamine.

The relative merits of dopamine and dobutamine remain undecided. Both agents appear to enhance renal perfusion. During alphaprodine anaesthesia dobutamine would seem to be at least as useful as dopamine and may have some advantage over the latter drug.

\section{SUMMARY}

The effects of dobutamine, a new catecholamine, have been studied during anaesthesia with halothane, halothane and nitrous oxide and alphaprodine. Renal blood flow is increased by dobutamine as are mean arterial pressure and heart rate. The increase in rate is less marked during alphaprodine anaesthesia than when halothane is administered. Dobutamine may prove a useful agent in the management of acute circulatory failure but it is capable of inducing dysrhythmias under the conditions of these experiments. 


\section{ACKNOWLEDGMENTS}

The authors wish to thank Dr. R. Tuttle and Eli Lilly and Co. for making dobutamine available to them and also to recognize the help and advice of their colleagues in the Departments of Pharmacology and Anaesthesia, U.B.C.

\section{REFERENCES}

1. Tuttle, R.R., Pollock, G.D., Todd, C., \& Tusk, R. Dobutamine: containment of myocardial infarction size by a new inotropic agent (abstr). Circulation 48 (Suppl. iv) IV-132 (1973).

2. Tuttle, R.R. Inotropic and chronotropic effects of dobutamine and isoproterenol on cat atria and papillary muscles at different temperatures (abstr). Fed. Proc. 33: 503 (1974).

3. Tuttle, R.R. \& Mills, J. Dobutamine: development of a new catecholamine to selectively increase cardiac contractility. Circ. Res. 36: 185 (1975).

4. Jewitt, D., Birkhead, J., Mitchell, A., \& Dollery, C. Clinical cardiovascular pharmacology of dobutamine a selective inotropic catecholamine. Lancet 2 (877) 363 (1974).

5. Vatner, S.F., McRitchie, R.J., \& Braunwald, E. Effects of dobutamine on left ventricular performance, coronary dynamics and distributions of cardiac output in conscious dogs. J. Clin. Invest. 53: 1265 (1974).

6. SutTon, J.A. Lancet I (7900) 226 (1975).

7. Holloway, G.A. \& Frederickson, E.L. Dobutamine, a new beta agonist. Anesth. Analg. (Clev.) 53: 616 (1974).

8. Bodem, R., Skelton, C.L., \& Sonnenblick, E.H. Effects of dobutamine on myocardial mechanics. Verl. Dtsch. Ges. Kreislanfforschg. 40:267 (1974).

9. MacCannell, K.L., McKay, J.L., Meyer, M.B., \& Goldberg, L.I. Dopamine in the treatment of hypotension and shock. New Eng. J. Med. 275: 1389 (1966).

10. Giffond, R.M., MacCannell, K.L., McKay, J.L., \& HAas, J.A. Changes in regional blood flows induced by dopamine and by isoproterenol during experimental hemorrhagic shock. Canad. J. Physiol. Pharmacol. 46: 847 (1968).

11. VAtner, S.F., Frankin, D., \& Braunwald, E. Effects of anaesthesia and sleep on circulatory response to carotid sinus nerve stimulation. Ann. J. Physiol. 200: 1249 (1971).

12. Vatner, S.F., Higcins, C.B., Franklin, D., \& Braunwald, E. Effects of cardiac depression and of anaesthesia on the myocardial action of cardiac glycoside. J. Clin. Invest. 50: 2585 (1971).

13. Robie, N.W., Nutrer, D.O., Moody, C., \& McNay, J.L. In vivo analysis of adrenergic receptor activity of dobutamine. Circ. Res. XXXIV: 663 (1974).

14. Daniele, H.B., Bagwell, E.E., \& Walton, E.P. Limitations of myocardial function by reduced coronary blood flow during isoproterenol action. Circ. Res. XXI: 85 (1967).

15. Beiser, G.D., Epstein, S.E., Goldstein, R.E., Stampler, M., \& Braunwald, E. Comparison of the peak inotropic effects of a catecholamine and a digitalis glycoside in the intact canine heart. Circ. XLII (1970).

16. Gunnar, R.M. \& Loeb, H.S. Use of drugs in cardiogenic shock and acute myocardial infarction. Circ. 45: 1111 (1972).

17. Lipp, H., Falicov, R.E., Resnikov, L., \& Kinc, S. The effects of dopamine on depressed myocardial function following coronary embolisation in the closed chest dog. Ann. Heart J. 84: 208 (1972). 